\title{
Polymorphism of major histocompatibility complex extended haplotypes bearing HLA-DR3 in patients with rheumatoid arthritis with gold induced thrombocytopenia or proteinuria
}

\author{
Dharam P Singal, Barbara Reid, Donna Green, Merl D’Souza, William G Bensen, \\ W Watson Buchanan
}

\begin{abstract}
The distribution of $\mathrm{DR3}$ and of extended haplotypes bearing DR3 was studied in three groups of subjects: 35 patients with rheumatoid arthritis (RA) with gold induced thrombocytopenia or proteinuria, 185 patients with $R A$ without these side effects, and 300 normal healthy controls. The extended haplotypes bearing DR3 were analysed with CDNA probes for $\mathrm{DR} \alpha, \mathrm{DR} \beta, \mathrm{DQ} \alpha$, and $\mathrm{DQ} \beta$ genes. The data showed that the prevalence of DR3 was significantly higher in patients who developed gold induced thrombocytopenia or proteinuria than in normal controls or patients with RA without these side effects. Distribution of three extended haplotypes bearing DR3 (B8,DR3; B18,DR3; non-B8,non-B18,DR3) in patients with RA with thrombocytopenia or proteinuria was significantly different from that in normal controls, but not from that in patients with RA without these toxic reactions. Southern blot analysis of DR, DQ genes with cDNA probes showed that the extended haplotype bearing B8,DR3, which carries DQA2.1 and DQB2.1 genes, was present in a significantly higher proportion of patients with RA with gold induced thrombocytopenia or proteinuria $(22 / 24,92 \%)$ than in patients with RA without these side effects (32/45, $71 \%)$ or normal subjects $(40 / 61,66 \%)$. The data suggest that the genomic region on chromosome 6 involved in susceptibility to gold induced thrombocytopenia or proteinuria should be extended to the DQA2, DQB2 gene loci.
\end{abstract}

Gold complexes are an established form of treatment for rheumatoid arthritis (RA). Numerous well controlled studies have shown the clinical efficacy of chrysotherapy in RA. ${ }^{1-5}$ Their use in the management of RA is limited by a fairly

Departments of Pathology and Medicine, McMaster University, and the Department of Medicine, St Joseph's Hospital, Hamilton, ON, Canada D P Singal B Reid

$M$ D'Souza

M G Bensen

W G Bensen

Correspondence to: Dr D P Singal, Department of Pathology, McMaster University, 1200 Main Street West, Hamilton, ON, Canada L8N $3 Z 5$.

Accepted for publication 25 October 1989 patients with RA with gold induced thrombocytopenia and proteinuria. ${ }^{19} 20$ In addition, Batchelor et al found a significantly higher incidence of DR3 in a family study of patients with RA who developed gold induced nephropathy. ${ }^{21}$ Despite these observations the nature of associations between development of gold induced thrombocytopenia and proteinuria and the presence of DR3 is not clear.

Extensive polymorphism in extended haplotypes bearing DR3 has been described recently by Southern blot analysis. ${ }^{22}{ }^{23}$ With cDNA probes for $\alpha$ and $\beta$ chain DR, DQ genes, two extended haplotypes bearing DR3 have been described in white populations. In addition, polymorphism in the DQA2 and DQB2 chain genes in extended haplotypes bearing DR3 can be easily identified. The objectives of this study were, therefore, to investigate the distribution of these extended haplotypes bearing DR3 by Southern blot analysis in patients with RA, with or without gold induced thrombocytopenia or proteinuria, and in normal subjects.

\section{Patients and methods}

Two hundred and twenty white patients with RA who attended the rheumatology clinics at the St Joseph's Hospital and the McMaster University Medical Center in Hamilton, Ontario, Canada were studied. All patients had moderate to severe definite classical seropositive RA. ${ }^{19} 2425$ These patients had earlier been treated with non-steroidal anti-inflammatory drugs and all had had an incomplete response requiring treatment with sodium aurothiomalate. Patients were treated with sodium aurothiomalate as recommended by Gottlieb ${ }^{26}$ that is, test doses of $10 \mathrm{mg}$ and $25 \mathrm{mg}$ intramuscularly (IM) one week apart, $50 \mathrm{mg}$ IM weekly doses for 20 consecutive weeks, maintenance regimen of $50 \mathrm{mg}$ IM every two weeks for three months, and thereafter $50 \mathrm{mg}$ IM every three weeks indefinitely. Patients were reviewed for $(a)$ thrombocytopenia (platelet count $\left.<100 \times 10^{9} / 1\right)$ and (b) significant proteinuria ( $>1 \mathrm{~g} /$ day). Eighteen patients who developed thrombocytopenia and another 17 who developed proteinuria after gold treatment were investigated for HLA-DR antigens. The remaining 185 patients with RA did not develop these side effects after gold treatment. Three hundred white, normal, healthy, unrelated subjects served as controls. Eight DR3 positive, homozygous B lymphoblastoid cell lines and members of 35 DR3 positive ( 20 normal controls and 15 patients with $\mathrm{RA}$ ) families were also studied. 
Peripheral blood lymphocytes were typed for HLA-A, B, C antigens by the microdroplet lymphocyte cytotoxicity test. ${ }^{27}$ HLA-DR, DQ typing was performed on a B cell enriched lymphocyte population separated from peripheral blood lymphocytes by the nylon wool method. ${ }^{27}$ HLA specificities were defined on the basis of reactivity with antisera in the 9th and 10th International Histocompatibility Workshops and with antisera in the Canadian Red Cross tissue typing trays.

Samples of genomic DNA $(7 \mu \mathrm{g})$, prepared from peripheral blood lymphocytes, ${ }^{28}$ were separately digested with 20 units of different restriction enzymes-for example, Bgl II, Bam $\mathrm{HI}$, etc, for 18 hours at $37^{\circ} \mathrm{C}$ with buffer conditions specified by the manufacturer (Bethesda Research Laboratories) and were electrophoresed on a $0.9 \%$ agarose gel in TAE buffer (40 mmol/l TRIS-acetate, $1 \mathrm{mmol} / \mathrm{l}$ EDTA) for 18 hours at $50 \mathrm{~mA} .^{28}$ Molecular weight markers on each gel contained $1.5 \mu \mathrm{g}$ of Hind III-digested lamba DNA (BRL). After electrophoresis, gels were denatured and neutralised before transfer (alkaline) to nylon membrane (Biotrace RP, Gelman) by Southern's method. ${ }^{29}$ After transfer, filters were prehybridised at $42^{\circ} \mathrm{C}$ and hybridised with oligonucleotide ${ }^{32} \mathrm{P}$ labelled $\mathrm{DR} \alpha, \mathrm{DR} \beta, \mathrm{DQ} \alpha$, and $\mathrm{DQ} \beta$ cDNA probes at $42^{\circ} \mathrm{C}$ for 48 hours. $^{30}$ After hybridisation, blots were first washed for five minutes twice at room temperature with $2 \times$ SSPE $(0.3 \mathrm{~mol} / 1 \mathrm{NaCl}, 20 \mathrm{mmol} / \mathrm{l}$ $\mathrm{NaH}_{2} \mathrm{PO}_{4} \cdot \mathrm{H}_{2} \mathrm{O}$, and $2 \mathrm{mmol} / \mathrm{l}$ EDTA); the filters were then washed for 15 minutes twice at $65^{\circ} \mathrm{C}$, once with $2 \times S S P E$ and $0.5 \%$ sodium dodecyl sulphate and once with $0.5 \times$ SSPE. The filters were autoradiographed with intensifying screens on Kodak XAR film at $-70^{\circ} \mathrm{C}$ for $3-10$ days.

Statistical analysis of the results was performed by the $\chi^{2}$ test. Relative risk (RR) values were calculated by the method of Woolf. ${ }^{31}$

Table 1: Prevalence (\%) of HLA-DR3 and DR4 in normal controls, in patients with rheumatoid arthritis $(R A)$ with thrombocytopenia or proteinuria, and in patients with $R A$ without these toxic reactions. Number (\%) of patients is shown

\begin{tabular}{llll}
\hline $\begin{array}{l}\text { HLA-DR } \\
\text { antigen }\end{array}$ & $\begin{array}{l}\text { Normal } \\
\text { healthy } \\
\text { controls } \\
(n=300)\end{array}$ & $\begin{array}{l}\text { Patients with } \\
\text { RA with } \\
\text { thrombocytopenia } \\
\text { or proteinuria } \\
(n=35)\end{array}$ & $\begin{array}{l}\text { Patients with } \\
\text { RA without these } \\
\text { toxic reactions } \\
(n=185)\end{array}$ \\
\hline DR3 & $61(20)$ & $24(69)^{*}$ & $\begin{array}{l}45(24) \\
\text { DR4 }\end{array}$ \\
$68(23)$ & $13(37)$ & $105(57) \dagger$ \\
\hline
\end{tabular}

*Significantly higher than normal controls $\left(p<10^{-6} ; R R=8 \cdot 55\right)$, and than patients with $R A$ without side effects $\left(p<10^{-6}\right.$; $\mathbf{R R}=6 \cdot 79$ ).

†Significantly higher than normal controls $\left(p<10^{-6} ; R R=4.48\right)$, and than patients with $R A$ with thrombocytopenia or proteinuria $(\mathrm{p}<0 \cdot 04 ; \mathrm{RR}=2 \cdot 22)$.
Results

The prevalence of HLA-DR antigens in the 35 patients with RA with gold induced thrombocytopenia or proteinuria was compared with that in $\mathbf{3 0 0}$ normal healthy subjects and 185 patients with RA who did not develop these toxic effects. No difference in the prevalence of DR antigens was found between patients with thrombocytopenia and those with proteinuria. The prevalence of two DR antigens, DR3 and DR4, was significantly different among these three groups (table 1). It is evident that the prevalence of DR3 was significantly higher in patients who developed gold induced thrombocytopenia or proteinuria than in normal healthy controls $\left(p<10^{-6} ; R R=8.55\right)$ or patients with RA without these side effects $\left(p<10^{-6}\right.$; $R R=6 \cdot 79$ ). Patients with $R A$ without these side effects had a significantly higher prevalence of DR4 than the normal controls $\left(\mathrm{p}<10^{-6}\right.$; $R R=4.48$ ) or patients with $R A$ with thrombocytopenia or proteinuria ( $<<0.04 ; R R=2 \cdot 22$ ). The higher prevalence of DR4 in patients with RA with thrombocytopenia or proteinuria (37\%) than in normal controls $(23 \%)$ was not significant $(p=0.06)$. No differences were found in the prevalence of the remaining $D R$ antigens in these three groups.

The Southern blot analysis of genomic DNA from DR3 positive homozygous B lymphoblastoid cell lines and members of 35 DR3 positive (20 normal controls and 15 patients with RA) families with $D R, D Q$ ( $\alpha$ and $\beta$ chain) cDNA probes showed that the HLA-B, DR, and DQ alleles in all examples of three different extended haplotypes bearing DR3 (B8,DR3; B18,DR3; and non-B8,non-B18,DR3) were fixed. Furthermore, we found a complete concordance between cDNA defined DR $(\mathrm{A} 1, \mathrm{~B} 1, \mathrm{~B} 3)$, DQ (A1,A2,B1,B2) alleles and serologically defined $B, D R$, and $D Q$ alleles in extended haplotypes bearing DR3. In addition, it was unequivocally possible to identify extended haplotypes bearing DR3 from phenotypes by restriction fragment length polymorphism (RFLP) in the remaining DR3 positive subjects.

Three extended haplotypes bearing DR3 were identifiable in normal healthy controls: $(a)$ B8,DR3; (b) B18,DR3; and (c) non-B8,nonB18,DR3. Table 2 shows the distribution of these three extended haplotypes in normal healthy controls, in patients with RA with gold induced thrombocytopenia or proteinuria, and in patients with RA without these side efects. It can be seen that the distribution of these extended haplotypes bearing DR3 in patients with RA with thrombocytopenia or proteinuria was significantly $(p<0.05)$ different from that in

Table 2: Distribution of extended haplotypes bearing HLA-DR3 in normal healthy controls, in patients with rheumatoid arthritis $(R A)$ with thrombocytopenia or proteinuria, and in patients with $R A$ without these toxic reactions after gold treatment

\begin{tabular}{lllll}
\hline & $\begin{array}{l}\text { Number of DR3 } \\
\text { haplotypes }\end{array}$ & $\begin{array}{l}B 8, D R 3 \\
\text { No (\%) }\end{array}$ & $\begin{array}{l}B 18, D R 3 \\
\text { No (\%) }\end{array}$ & $\begin{array}{l}\text { Non-B8,non-B18,DR3 } \\
\text { No (\%) }\end{array}$ \\
\hline $\begin{array}{l}\text { Normal healthy controls } \\
\begin{array}{l}\text { Patients with RA without } \\
\text { toxic reactions }\end{array}\end{array}$ & 61 & $40(66)$ & $6(10)$ & $15(25)$ \\
$\begin{array}{l}\text { Patients with RA with } \\
\text { thrombocytopenia or proteinuria* }\end{array}$ & 45 & $32(71)$ & $3(7)$ & $10(22)$ \\
\hline
\end{tabular}

*Distribution of extended haplotypes bearing DR3 significantly different from that in normal healthy controls $(p<0.05)$. 


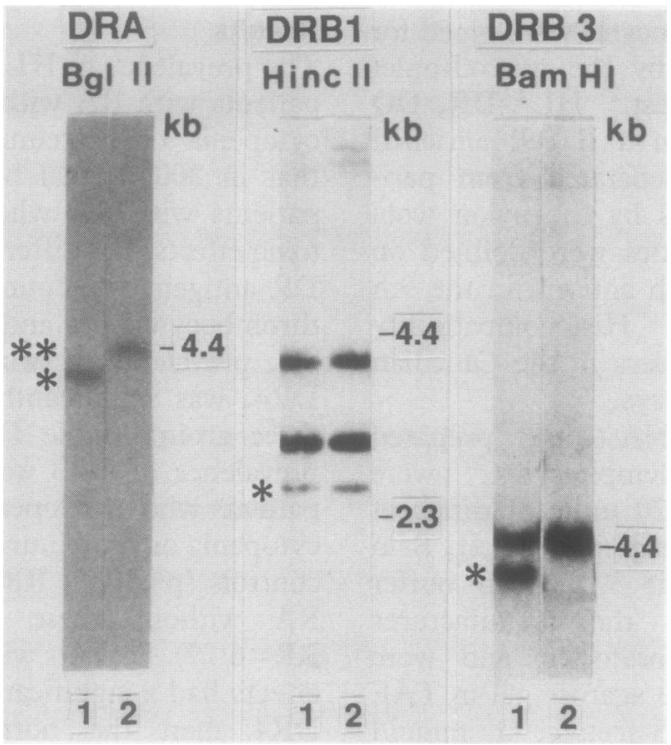

Figure 1: Southern blots of DNA from $D R 3$ positive homozygous cell lines, digested with restriction endonucleases and hybridised with $D R \alpha$ and $D R B C D N A$ probes. Lane $1=C o x(B 8, D R 3)$; lane 2=DUCAF $(B 18, D R 3)$. $D R A:{ }^{*}=D R A 1,{ }^{* *}=D R A 2 ; D R B 1:{ }^{*}=D R B 1$; $D R B 3: *=D R B 3.1$.

the normal healthy controls, but not from that in patients with RA without adverse reactions.

We examined the RFLP in the $\alpha$ and $\beta$ chain genes of the DR, DQ subregions of the extended haplotypes bearing DR3. In the DR subregion two extended haplotypes bearing DR3 were identifiable as follows (fig 1):

1. B8,DR3 and non-B8,non-B18,DR3: DRA1 (Bgl II $=4.20 \mathrm{~kb}$; Eco RV=8.20 kb), DRBl (Hinc II $=2.50 \mathrm{~kb})$, DRB3.1 (Bam HI $=4.00 \mathrm{~kb}$; Hind III $=2.60 \mathrm{~kb} ;$ Pvu II $=5.60 \mathrm{~kb}$; Pst $\mathrm{I}=1.07$ kb).

2. B18,DR3: DRA2 (Bgl II $=4.50 \mathrm{~kb}, \mathrm{Eco}$ $R V=12.50 \mathrm{~kb}$ ), DRB1 (Hinc $I I=2.50 \mathrm{~kb}$ ), DRB3.2 (Pvu II =5.40 kb, Eco RI=2.90 kb).

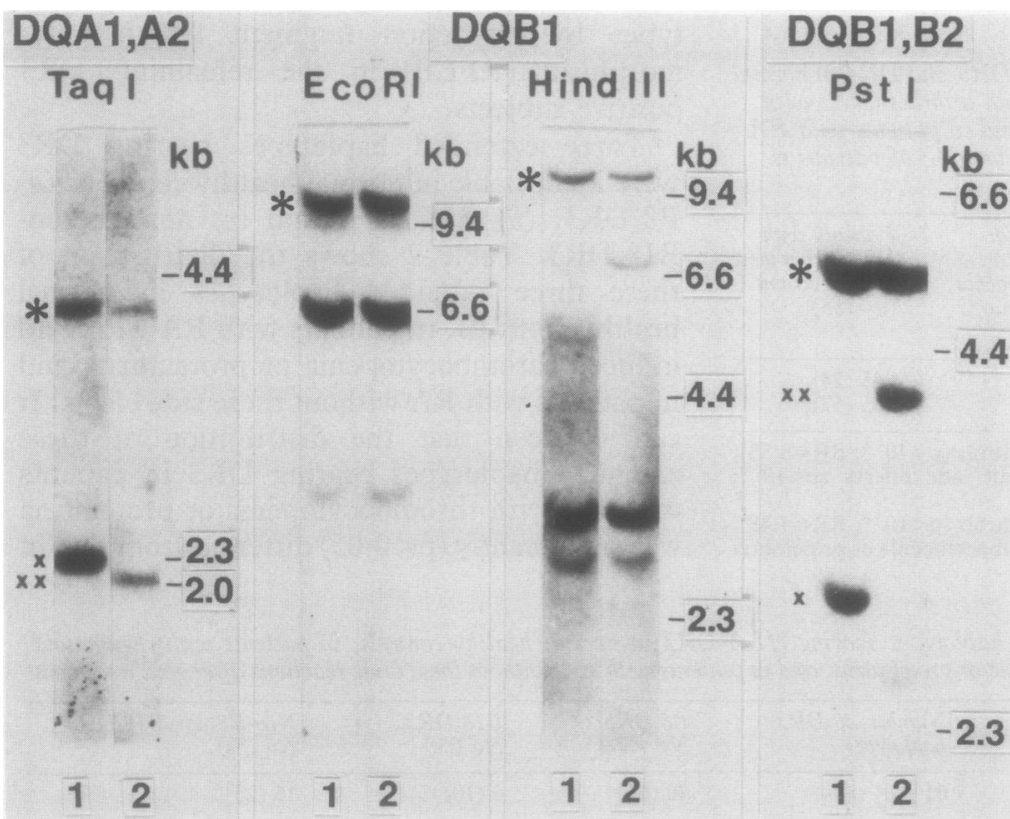

Figure 2: Southern blots of DNA from DR3 positive homozygous cell lines, digested with restriction endonucleases and hybridised with $D Q \alpha$ and $D Q \beta c D N A$ probes. Lane $I=C o x$ $(B 8, D R 3) ;$ lane $2=D U C A F(B 18, D R 3) . D Q A:^{*}=D Q A 1,{ }^{x}=D Q A 2.1,{ }^{x x}=D Q A 2 \cdot 2$ $D Q B:{ }^{*}=D Q B 1,{ }^{x}=D Q B 2.1,{ }^{x x}=D Q B 2.2$.
Similarly, these two extended haplotypes bearing DR3 were demonstrable for DQA1 and DQB1 chain genes (fig 2). The distribution of these two types of extended haplotypes bearing DR3 (B8,DR3 and non-B8,non-B18,DR3: $B 18, D R 3)$ in normal subjects (55:6), patients with RA with thrombocytopenia or proteinuria (23:1), patients with RA without these side effects (42:3) was essentially similar $\left(\chi^{2}=0 \cdot 18\right.$ to $0 \cdot 73$; NS).

Southern blots were then analysed for distribution of RFLP for DQA2 and DQB2 genes. Two DQA2 genes were identifiable; one DQA2.1 (Taq $I=2.25 \mathrm{~kb}$; Pst $I=8.00 \mathrm{~kb}$ ) correlated with the B8,DR3 haplotype, and the other DQA2.2 (Taq $I=2 \cdot 15 \mathrm{~kb}$; Pst $I=6.84 \mathrm{~kb}$ ) was associated with B18,DR3 and non-B8,nonB18,DR3 alleles (fig 2). Similarly, two DQB2 genes, DQB2.1 associated with B8,DR3 (Pst $I=2.90 \mathrm{~kb})$ and DQB2.2 with B18,DR3 and non-B8,non-B18,DR3 (Pst $I=4 \cdot 10 \mathrm{~kb}$ ), were demonstrable (fig 2). Thus the combined analysis for DR and DQ ( $\alpha$ and $\beta$ chain) genes distinguished three extended haplotypes bearing DR3: B8,DR3; B18,DR3; and non-B8,nonB18,DR3.

Based on RFLP for DQA2 and DQB2 chain genes, two extended haplotypes bearing DR3, B8,DR3 and non-B8,DR3 (including B18,DR3 and non-B8,non-B18,DR3), were demonstrable. The distribution of the extended haplotype bearing B8,DR3, which carries the DQA2.1 and DQB2.1 genes in patients with RA with thrombocytopenia or proteinuria (92\%), was significantly different from its distribution in patients without these side effects $(71 \% ; \mathrm{p}<0.05)$, and in normal healthy subjects $(66 \% ; \mathrm{p}<0.015)$.

\section{Discussion}

The data in this study show that the incidence of DR3 was significantly higher in patients with RA who developed gold induced thrombocytopenia or proteinuria than in normal healthy controls or patients with RA who did not develop these side effects after gold treatment. In addition, patients with $\mathrm{RA}$ without these side effects had a significantly higher prevalence of DR4 than the normal controls or patients with RA with thrombocytopenia or proteinuria. The higher prevalence of DR4 in patients with RA with thrombocytopenia or proteinuria was not statistically different from that in normal controls. The distribution of three extended haplotypes bearing DR3 in patients with RA with thrombocytopenia or proteinuria was significantly different from that in normal healthy controls, but not from that in patients with RA without these toxic reactions. Southern blot analysis of HLA-D region genes with $\alpha$ and $\beta$ chain $c D N A$ probes showed that the B8,DR3 extended haplotype, which carries DQA2.1 and DQB2.1 genes, was present in a significantly higher proportion in patients with $R A$ with thrombocytopenia or proteinuria than in normal subjects or patients with RA without these gold induced side effects. The data suggest that the genomic region on chromosome 6 involved in susceptibility to gold induced thrombocytopenia 
or proteinuria should be extended to the DQA2, DQB2 gene loci.

A number of investigators have found a correlation between DR3 and gold induced thrombocytopenia or proteinuria. ${ }^{9-15}{ }^{19-21}$ On the other hand, three reports could not confirm that the patients with DR3 were more likely to have toxic reactions to gold than the patients without these antigens. ${ }^{16-18}$ These reported differences may be related to patient selection (racial factors, seropositive, or seronegative) and to the gold preparation used. The results in our study are in agreement with earlier reports, which showed patients with RA carrying DR3 are at a higher risk of developing gold induced thrombocytopenia or proteinuria. In addition, the present data extend the earlier results by showing that the distribution of extended haplotypes bearing DR3 in patients with RA with thrombocytopenia or proteinuria was significantly different from that in normal healthy controls.

The HLA-D region of human major histocompatibility complex consists of multiple gene loci encoding $\alpha$ and $\beta$ subunits that form $\alpha \beta$ heterodimers. The HLA-D region genes are arranged in a block consisting of several subregions including $D R, D Q$, and $D P$, with each subregion containing at least one $\alpha$ chain and one $\beta$ chain gene. In recent years RFLP analysis of the HLA-D region genes (DR (A,B1,B3,B4); DQ $(A 1, A 2, B 1, B 2)$ ) has developed into a powerful tool for genomic typing. A number of investigators have examined the polymorphism of extended haplotypes bearing DR3 by Southern blot analysis, ${ }^{22} 23^{32-34}$ and the polymorphism detected by RFLP analysis of DR, DQ genes in these DR3 extended haplotypes correlated with phenotypic polymorphism recognised by serology. 22 23 $32-35$ These data strongly suggest that it is possible to identify three different extended haplotypes bearing DR3 from phenotypes by RFLP. In this study we examined members of $35 \mathrm{DR} 3$ positive families, including 15 families of patients with RA. In the remaining cases we used Southern blot analysis of genomic DNA, as suggested by a number of investigators, ${ }^{22} 233^{32-35}$ for the identification of extended haplotypes bearing DR3. The distribution of different extended haplotypes bearing DR3 in normal subjects and in patients with RA in this study was the same as that found by other investigators in normal subjects ${ }^{36}{ }^{37}$ and in patients with RA. ${ }^{21} 38$ In addition, in an earlier study all (15 of 15) DR3 positive patients with RA who developed gold induced nephropathy carried the B8,DR3 extended haplotype. ${ }^{21}$ Our data, therefore, confirm the earlier results and extend them as the distribution of DQA2 and DQB2 chain genes on haplotypes bearing DR3 in patients with RA with thrombocytopenia or proteinuria was significantly different from that in normal healthy controls or in patients with RA without these gold induced toxic reactions.

Because of linkage disequilibrium between polymorphic alleles of HLA genes, certain combinations of alleles are inherited as extended haplotypes. Several independent examples of extended haplotypes bearing DR3 have recently been examined. ${ }^{22} 2334$ The results showed that these independent examples belong to an extended haplotype bearing DR3 and are similar in RFLP patterns, suggesting that if an allele can be divided into subtypes, most examples of extended haplotypes belonging to a subtype are similar. These data suggest that alleles in B, $D R, D Q$ regions of extended haplotypes bearing DR3 are fixed and thus support the extended haplotype theory. ${ }^{22}$ The results in this study suggest that patients with RA carrying the extended haplotype bearing B8,DR3 are at a higher risk of developing gold induced thrombocytopenia or proteinuria than the patients positive for B18,DR3 or non-B8,non-B18,DR3 haplotypes. Furthermore, the data suggest that the genomic region on chromosome 6 involved in susceptibility to gold induced thrombocytopenia or proteinuria should be extended to the DQA2 and DQB2 gene loci.

HLA-D region antigens play a crucial part in regulation of immune response and in pathogenesis of diseases. The results in our study suggest that subjects carrying a particular extended haplotype bearing DR3 may display disease associations that differ from those of subjects positive for other DR3 extended haplotypes. Similar results have been reported for gluten sensitive enteropathy, where only the B8,DR3 haplotype, and not the other DR3 haplotypes, is increased in patients. ${ }^{39}$ In contrast, both B8,DR3 and B18,DR3 extended haplotypes are increased in insulin dependent diabetes mellitus. ${ }^{4041}$

This work was supported by research grants from the Arthritis Society and the Medical Research Council of Canada. The DRa (pII- $\alpha-1), \mathrm{DR} \beta$ (pII- $\beta-3$ ), and DQ (pII- $\beta-1)$ cDNA probes were kindly given by Dr P A Peterson, Uppsala, Sweden and the DQ (p DCal07) probe by Dr K Tsuji, Kanagawa, Japan.

1 Empire Rheumatism Council. Gold therapy in rheumatoid arthritis: report of a multicentre controlled trial. Ann Rheum Dis 1960; 19: 95-119.

2 Empire Rheumatism Council. Gold therapy in rheumatoid arthritis: final report of a multicentre controlled trial. $A n n$ Rheum Dis 1961; 20: 315-34.

3 The Cooperative Clinics Committee of the ARA. A controlled trial of gold salt therapy in rheumatoid arthritis. Arthritis Rheum 1973; 16: 353-8.

4 Sigler J W, Bluhm G B, Duncan H, Sharp J T, Ensign D C, McCrum W R. Gold salts in the treatment of rheumatoid arthritis: a double-blind study. Ann Intern Med 1974; 80: arthritis:

5 Ward J R, William H J, Egger M J, et al. Comparison of auranofin, gold sodium thiomalate and placebo in the treatment of rheumatoid arthritis. A controlled clinical trial. Arthritis Rheum 1983; 26: 1303-15.

6 Hartfall S J, Garland H G, Goldie W. Gold treatment of arthritis: a review of 900 cases. Lancet 1937; ii: 784-8, $838-42$.

7 Sorensen B. Case of fatal thrombopenia about 10 months after treatment with a gold preparation. Acta Med Scand 1951; 141: 27-35.

8 Canada A T. Gold induced thrombocytopenia. Am $\mathcal{f}$ Hosp Pharm 1973; 30: 340-2.

9 Panayi G S, Wooley P, Batchelor J R. Genetic basis of rheumatoid disease: HLA antigens, disease manifestations, rheumatoid disease: HLA antigens, disease manifestations,

10 Wooley P H, Griffin J, Panayi G S, Batchelor J R, Welsh K I, Gibson T J. HLA-DR antigens and toxic reactions to Gibson $T \mathrm{~J}$. HLA-DR antigens and toxic reactions to sodium aurothiomalate and D-penicillamine in patients
with rheumatoid arthritis. $N$ Engl $f$ Med $1980 ; 303: 300-2$.

11 Coblyn J S, Weinblatt M, Holdsworth D, Glass D. Goldinduced thrombocytopenia. Ann Intern Med 1981; 95: 178-81.

2 Bardin T, Dryll A, Debeyre N, et al. HLA system and side effects of gold salts and D-penicillamine treatment of rheumatoid arthritis. Ann Rheum Dis 1982; 41: 599-601.

13 Gran J T, Husby G, Thorsby E. HLA-DR antigens and gold toxicity. Ann Rheum Dis 1983; 42: 63-6.

14 van Riel P L C M, Reekers P, van de Putte L B A, Gribnau F W J. Association of HLA antigens, toxic reactions and therapeutic responses to auranofin and toxic reactions and patients with rheumatoid arthritis. Tissue Antigens 1983; 22: 194-9. 
15 Hakala $M$, van Assendelft A $H$, Ilonen J, Jalava $S$, Tiilikainen A. Association of different HLA antigens with various toxic effects of gold salts in rheumatoid arthritis. Ann Rheum Dis 1986; 45: 177-82.

16 Magoos F L, Klemp P, Meyers O L, Briggs B. Gold therapy in rheumatoid arthritis. S Afr Med F 1981; 59: 971-4.

17 Karr R W, Rodey G E, Lee T, Schwartz B D. Association of HLA-DRw4 with rheumatoid arthritis in black and white patients. Arthritis Rheum 1980; 23: 1241-5.

18 Dequeker $J$, van $W$ anghe $P$, Verdickt $W$. A systematic survey of HLA-A,B,C, and D antigens and drug toxicity in rheumatoid arthritis. $\mathcal{F}$ Rheumatol 1984; 11: 282-6.

19 Bensen W G, Moore N, Tugwell P, D'Souza M, Singal D P. HLA antigens and toxic reactions to sodium aurothiomalate in patients with rheumatoid arthritis. $\mathcal{F}$ Rheumatol 1984; 11: $358-61$.

20 Adachi J D, Bensen W G, Kassam Y, et al. Gold induced thrombocytopenia: 12 cases and a review of the literature. Semin Arthritis Rheum 1987; 16: 287-93.

21 Batchelor J R, Dodi I A, Woo P, Panayi G, Ansell B M, Williams P L. A family study of gold-induced nephropathy in patients with rheumatoid arthritis. In: Albert $\mathrm{E} D$, Baur in patients with rheumatoid arthritis. In: Albert E D, Baur Heidelberg: Springer, 1984: 375-8.

22 Singal D P, Green D, Reid B, D'Souza M. Polymorphism of three HLA-DR3-bearing major histocompatibility complex extended haplotypes. Immunogenetics 1989; 29: 277-80.

23 Westcott M Z, Awdeh Z L, Yunis E J, Alper C A. Molecular analysis distinguishes two HLA-DR-bearing major histocompatibility complex extended haplotypes. Immunogenetics 1987; 26: 370-4.

24 Singal D P, D'Souza M, Reid B, Bensen W G, Kassam Y B, Adachi J D. HLA-DQ beta-chain polymorphism in HLADR4 haplotypes associated with rheumatoid arthritis. Lancet 1987; ii: 1118-20.

25 Ropes $M$ W. Diagnostic criteria for rheumatoid arthritis: 1958 revision. Ann Rheum Dis 1959; 18: 49-53.

26 Gottlieb N L. Gold compounds in the rheumatoid diseases. In: Kelley W N, Harris E D, Ruddy S, Sledge C B, eds. Textbook of rheumatology. Philadelphia: Saunders, 1981: 796-814.

27 Terasaki P I, Bernoco D, Park M S, Ozturk G, Iwaki Y. Microdroplet testing for HLA-A, -B, -C, and -D antigens. Am f Clin Pathol 1978; 69: 103-20.

28 Maniatis T, Fritsch E F, Sambrook J. Molecular cloning. New York: Cold Spring Harbor Laboratory, 1982.

29 Southern E M. Detection of specific sequences among DNA fragments separated by gel electrophoresis. $\mathcal{J}$ Mol Biol 1975; 98: 503-17.

30 Singal D P, Butler L, Lamontagne L. Identification of types of HLA-DR2 by Southern blot analysis. Tissue Antigens 1986; 28: 29-40.

31 Woolf $\mathrm{B}$. On estimating the relation between blood group and disease. Ann Hum Genet 1955; 19: 251-3.

32 Stetler D, Grumet F C, Erlich H A. Polymorphic restriction endonuclease sites linked to the HLA-DRu gene: localization and use as genetic markers of insulin-dependent diabetes. Proc Natl Acad Sci USA 1985; 82: 8100-4.

33 Chatila M, Luyrink L, McEleney J, Spies T, Strominger J L, Glass D N. Restriction fragment length polymorphisms and an HLA-DRw52-associated split. Hum Immunol 1988; 21: 89-97.

34 Hurley $\mathrm{C}$ K, Gregersen $\mathrm{P}$, Steiner $\mathrm{N}$, et al. Polymorphism of the HLA-DR region in American blacks. A DR3 haploA recombination. 7 Immunol 1988; 140: 885-92.

35 Festenstein H, Awad J, Hitman G A, et al New HLA DNA polymorphisms associated with autoimmune diseases. Nature 1986; 322: 64-7.

36 Baur M P, Neugebauer M, Albert E D. Reference tables of two-locus haplotype frequencies for all MHC marker loci. In: Albert E D, Baur M P, Mayr W R, eds. Histocompatibility testing 1984. Heidelberg: Springer, 1984: 677-760.

37 Baur M P, Danilovs J A. Reference tables of two and threelocus haplotype frequencies for HLA-A,B,C,DR,BF, and GLO. In: Terasaki P I, ed. Histocompatibility testing 1980. Los Angeles: UCLA Tissue Typing Laboratory, 1984: 994-1210.

38 Fielder A H L, Ollier W, Lord D K, et al. HLA class III haplotypes in multicase rheumatoid arthritis families. Hum haplotypes in multicase r.

39 Alper C A, Fleischnick E, Awdeh Z, Katz A J, Yunis E J. Extended major histocompatibility complex haplotypes in patients with gluten-sensitive enteropathy. $\mathcal{f}$ Clin Invest 1987; 79: 251-6.

40 Todd J, Bell J I, McDevitt H O. HLA-DQß gene contributes to susceptibility and resistance to insulin-dependent diabetes mellitus. Nature 1987; 329: 599-604.

41 Zerbib A, Molvig J, Thomsen M, et al. Restriction fragment ength polymorphism of HLA and non-HLA genes in DR $3 / 4$ heterozygous Danish insulin-dependent diabetic patients and healthy individuals: reassessment of the influence of $u$ n-linked polymorphic loci, and new DQw3 haplotypes. Dis Markers 1989; 7: 27-41. 